\title{
Profit-driven and demand-driven investment growth and fluctuations in different accumulation regimes.
}

\author{
Giovanni Dosi*1 ${ }^{*}$ Mauro Sodini ${ }^{\dagger 2}$ and Maria Enrica Virgillito ${ }^{\ddagger 1}$ \\ ${ }^{1}$ Sant'Anna School of Advanced Studies \\ ${ }^{2}$ University of Pisa
}

\begin{abstract}
The main task of this work is to develop a model able to encompass, at the same time, Keynesian, demand-driven, and Marxian, profit-driven, determinants of fluctuations. Our starting point is the Goodwin model (1967), rephrased in discrete time and extended by means of a coupled dynamics structure. The model adds the combined interaction of a demand effect, which resembles a rudimentary first approximation to an accelerator, and of a hysteresis effect in wage formation in turn affecting investments. Our model yields "business cycle" movements either by means of persistent oscillations, or chaotic motions. These two different dynamical paths accounting for the behaviour of the system are influenced by its (predominantly) profit-led or wage-led structures.
\end{abstract}

Keywords: Endogenous Growth; Business Cycles; Investment; Predator-Prey Dynamics; Aggregate Demand; Accelerator; Complex Systems; Non-linearity; Chaos Theory.

JEL Classification: E32, E11, E12, E17

\section{Introduction}

Capitalistic growth proceeds through "fits and starts" as Schumpeter (1934) put it. Indeed fluctuations are permanent feature of modern economic dynamics. But what drives

${ }^{*}$ gdosi<at>sssup.it (corresponding author)

${ }^{\dagger}$ m. sodini<at>ec.unipi.it

${ }^{\ddagger}$ m.virgillito<at>sssup.it 
them? As known, the theory offers two ensembles of answers depending on whether fluctuations are seen as driven by exogenous shocks or by endogenous determinants. In this work we shall focus on the latter explanation. The main task is to develop a model able to encompass, at the same time, Keynesian - demand-driven - and Marxian - profitdriven - determinants of fluctuations. Our starting point is the Goodwin (1967) model, rephrased in discrete time and extended by means of a coupled dynamics structure. The model adds the combined interaction of a demand effect, which resembles a rudimentary first approximation to an accelerator, and of a hysteresis effect in wage formation in turn affecting investments. Our model yields "business cycle" movements either by means of persistent oscillations, or chaotic motions. The different dynamical paths accounting for the behaviour of the system are influenced by its (predominantly) profit-led or wage-led structures (in tune with the insightful Bhaduri and Marglin, 1990).

Just to recall, models of exogenously driven fluctuations, with roots in the classic Frisch (1933) basically, entail a story of a system in equilibrium, hit by an exogenous (generally supply-side) shock to which it adjusts (Louca, 2001). The fluctuations are the work of such adjustments and in some versions, such as Real Business Cycle models, are themselves equilibrium phenomena.

Conversely, alternative and diverse stream of interpretations, which will be our concern here, see fluctuations as an intrinsic feature of capital accumulation (as in Marx and in Goodwin), of technological innovation (Marx and Schumpeter) or of aggregate demand formation (Keynes and the Keynesians).

Given endogeneity, another issue regards the linearity or non-linearity of the relations and the inadequacy of the former to represent persisting fluctuations, that are not explosive nor damped. The early models by Kalecki (1935), Samuelson (1939a), Harrod (1939), Kaldor (1940), Domar (1946), Goodwin (1951), Pasinetti (1960), Goodwin (1967) among others, belong to the family of explicitly dynamic models. All of them try to account the business cycles movements as the result of the interactions among aggregate variables, but while the "Marx-Goodwin" perspective is built under classical assumptions that emphasize the role of supply, and in particular profits, in determining capital accumulation, all the others focus on the role of variation in consumption and directly or indirectly investment, hence in demand, in boosting economic growth. Building on these original models a literature has developed focusing on the non-linearity of such relationships and studying the ensuing dynamical system (see Medio, 1979; Lorenz, 1993; Sordi, 1999; Puu and Sushko, 2006; Yoshida and Asada, 2007 among others). Non-linearities are indeed fully embodied in representations of the economy as a 'complex evolving system' (Arthur et al., 1997; Kirman, 2011; Rosser, 1999). Granted that, there is a delicate analytical challenge involved here. Low dimensional models (which are necessarily non-microfounded, as they abhor any "representative agent" short-cuts) are bound to capture in their ag- 
gregate laws of motion something specific to particular socio-economic set-ups. So for example, the relation between distributive shares, investment and growth is plausibly likely to differ, also in the aggregate, between say, Victorian England, vs post WWII US vs nowadays China... Here we intend to contribute to such comparative analyses of institutionally diverse dynamical systems.

In Section 2 we analyze the dynamical paths generated by Classic-Marxian and Keynesian fluctuations, comparing the behaviour of conservative and dissipative systems in the description of macro phenomena. In Section 3 we discuss strengths and limitations of the Goodwin (1967) Growth Cycle which will be the starting point of our analysis. Section 4 presents a discrete time, slightly modified, version of Goodwin's model. Its structural instability will motivate our generalization (Section 5), where we introduce, along with the "classical' elements of a "class struggle" model, also a demand effect capturing a Keynesian interpretation of the dynamics of investment and output. Section 6 concludes.

\section{2 "Classical" and Keynesian fluctuations}

As already mentioned, Marxian and Keynesian approaches both highlight the instability of the system and both perspectives attempt to describe booms, stagnations and downturns as direct consequences of the very nature of capitalist dynamics. However, the two families of models differ in both the formal modeling investments - ultimately, conservative vs. dissipative systems - , and in the historical reference to different "archetypes of capitalism" of socio-economics relations and accumulation regimes (in addition to a vast French-language literature on the Regulation approach, see in English, Boyer, 1988a and Boyer, 1988b).

So, in terms of historical archetypes, models of Marxian inspiration address a sort of "Smithian-Victorian" (or "Classic") form of capitalism, are usually supply-led economies, where the process of profits accumulation plays the role of driver of the system. Conversely, Keynesian models are demand-led economies where wages accumulation and expected demand are the main engines of the investment activity.

In the "Classic" archetype, prices are competitive, wages are held down by an almost unlimited potential supply of labour - as from the original Marxian notion of the 'industrial reserve army' - , and are possibly dependent, as in Marx and Goodwin, upon unemployment rates affecting the bargaining strength of workers themselves. This is the competitive wage-labour nexus which the 'Regulation School' flags as one of the fundamental ingredients of Victorian capitalism, with little institutional representation for workers, no explicit indexation mechanism of wages, neither on productivity nor inflation, and the market playing a major role in wage determination. In a complementary 
mechanism, accumulation is driven by re-invested profits. Individual capitalists are too small to consider individual past demands as indicators of future demand. In fact, a "competitive approximation" is the ensemble of capitalists investing and producing as much as they are allowed by past profits (with 'imperfections' on the financial markets, as we would say nowadays, so massive and so obvious, not to be talked about!). And add to that a propensity to consume by capitalists themselves at the very least lower than workers: even without Protestant ethic, most models just need that to yield the desired qualitative properties!

Historically, a deep regime transition occurred roughly from the beginning of the 20th century to its fully completion after WWII, involving permanent changes in the working of the major markets (for labour, goods and finance) as well as in the relations between the State and the private actors (associated also with major changes in production technologies and forms of corporate organizations whose analysis is beyond the scope of this paper. See, however Boyer, 1988a and Boyer, 1988b for a succinct overview). In the new regime, - call it Fordist, or corporatist, or Keynesian - , supply is dominated by mass production within oligopolistic price-making firms. Wages stop being primarily governed by the rates of unemployment but, sustained by collective bargaining, became linked to the rates of inflation and of productivity growth. Moreover, far from being just a cost, they became an essential component of demand which in turn drives investment decisions.

The formal representation of the dynamic of the competitive accumulation regime is satisfactorily captured by a fluctuating conservative system to which is superimposed an exogenous drift (standing for technical progress). Goodwin's Growth Cycle belongs to this class of models: a Lotka-Volterra type of interaction between workers and capitalists making conflicting claims upon aggregate output induces a cycle in the distributive shares and with that in investment and thus in the rates of growth. The simplest visual image of it is a sort of "wheat-wheat" model wherein the total output is made of wheat which can be appropriated by the workers as wages and consumed, or by the capitalists as profits and invested. In that, no portion of the total amount of wheat is left unused and of course one cannot eat or invest more wheat than it is produced. This is indeed a basic feature of the conservative nature of the system. The property however does not apply to the representation of Keynesian regime wherein it is demand (past and expected) which drives the growth or contraction of the system itself. A more adequate account is in terms of dissipative systems which can easily undergo more complex dynamics (such as chaotic ones) and, under certain conditions, can self-organize and generate orderly patterns as emergent from out-of-equilibrium fluctuations (Nicolis and Prigogine, 1977). The term dissipative stems from the analysis of physical systems characterized by a permanent input of energy which dissipates over time. If the energy input is in- 
terrupted, the system collapses to some equilibrium state. However, as distinct feature, socio-economic systems characterized by endogenous innovation systematically violate any general principle of conservation. In a way you can get out more than you put in or conversely you can get out less than you put in. Evolutionary processes characterized by learning and innovation dynamics, increasing returns, accumulation of knowledge are potential drivers of "getting more out of less", while Keynesian endogenous generation of demand and its associated possibilities of structural crises entail also the chance of "getting less" out of the potential resources.

In what follows we are going to start from the Goodwin model with a conservative"Marxian" structure and add an endogenous (formally dissipative) mechanism of demand generation in order to account at the same time for Keynesian and Classical-Marxian engines as sources of macro-fluctuations. ${ }^{1}$

\section{The Goodwin model: strengths and limitations}

Goodwin (1967) represents the first formalization of the distributive conflict between profits and wages, with product market-clearing, opposed to a Keynesian, demand-driven perspective. Capitalists save and reinvest all their profits, without any concern about over-accumulation. Workers spend all income they receive.

According to the Marxian theory, crises can occur at least for two different causes related to capital accumulation, namely, overproduction crises or "class struggle" crises. Overproduction crises occur when a high rate of profit accumulation determines an excess of supply, for a given wage level. In this case, capitalists suffer some losses because they are not able to sell all their production. This driver of fluctuations is neglected by Goodwin-type models. Conversely, "class struggle" crises happen when capital accumulation determines an increase in labour demand, leading to an employment increase, so strengthening workers' bargaining power, yielding wage increases, a drop of the profit rate and lower capital accumulation. In turn, this drives to lower production, lower employment, lower wages and a higher profit rate. This cyclical and opposite movement of wages and profits, present in all classical economists, is indeed central to the Marx theory of capitalist instability. This classical view of capitalist system underlies the model of economic fluctuations driven by the interrelations between profits and wages. And it is the core of Goodwin's Growth Cycle model:

It has long seemed to me that Volterra's problem of the symbiosis of two populations, partly complementary, partly hostile, is helpful in the understanding of the dynam-

\footnotetext{
${ }^{1}$ For an exhaustive discussion of dynamical systems in economics together with the formal differences between conservative and dissipative systems see Medio (1992) and Lorenz (1993).
} 
ical contradictions of capitalism, especially when stated in a more or less Marxian form. (Goodwin, 1967)

As mentioned, Goodwin (1967) accounts for technical change in the form of a timedependent drift, (and the model can be extended to an endogenous - in principle investment embodied - technical change, preserving its basic Lotka-Volterra structure. See Silverberg and Lehnert, 1994 for a masterpiece evolutionary investigation of the predator-prey model).

Although it is particularly insightful from an economic point of view, the model however presents a technical drawback: it is structurally unstable. Structural instability entails that every minimal modification of the functional form may destroy its fundamental characteristics, in our case regular and persistent fluctuations of the aggregate variables of interest. ${ }^{2}$ A consequence is that in general if one tries to generalize the original Goodwin (1967) system, the model loses the possibility of accounting for regular economic cycles. The Growth Cycle model presents an other drawback, again due to the nature of the dynamical system: the amplitude of oscillations is entirely due to initial conditions. Trajectories that start close to the stationary point have a small amplitude. Vice versa, trajectories starting from points far from it have wide oscillations. In the literature one finds a few attempts to overcome the structural instability, moving from conservative toward dissipative structures of the system (see Desai, 1974; Velupillai, 1979; Wolfstetter, 1982; Flaschel, 1984; Pohjola, 1981). Except for the latter, all these contributions introduce further determinants into the wage equation.

Moreover, the original Goodwin (1967) and the most part of the foregoing refinements live in a continuous time frame (contributions that use a discrete time framework are Pohjola, 1981, Goodwin, 1989 himself (pg. 32), Sordi, 1999 and Canry, 2005). In the following we will explore a discrete time formulation being in our view more economically appropriate. After all, investment is a time consuming activity: equipments have to be ordered, purchased, manufactured, introduced in production and so forth. Entrepreneurs usually make investment plans setting today how much to invest tomorrow. A considerable time interval exists between investment decision and capital production/utilization. Investment and disinvestment activities cannot happen in an instantaneous way, as already pointed out by Kalecki (1935). Wage bargaining is a process that takes time as well: labour contracts cannot be instantaneously modified. ${ }^{3}$

With respect to the existing literature, Pohjola (1981) substitutes the original Phillips

\footnotetext{
${ }^{2}$ Conversely, a dynamical system is structurally stable if for every sufficiently small perturbation of the vector field the perturbed system is topologically equivalent to the original system.

${ }^{3}$ In order to capture discrete economic delays interesting contributions have proposed a continuoustime framework with delays: see Manfredi and Fanti (1999), Tebaldi and Colacchio (2007) and Yoshida and Asada (2007)
} 
curve equation with the Kuh (1967) specification, so that it is not the wage share but the level of wage which depends positively upon employment. This apparent slightly modification induces dramatic changes in the dynamics of the model: it reduces the original two dimensional system into a one dimensional logistic map which shows simple or chaotic behaviour, according to different parameter constellations. Another discrete time version is in Canry (2005) which bears some analogy with what we shall do in the following. The model refines a "classical" investment equation with a demand-effect.

\section{A discrete time version of the Goodwin Growth Cycle model}

Let us start by considering a discrete time reformulation of the original Goodwin (1967) model. We assume that:

$$
Y_{t}=A K_{t}
$$

i.e. a constant output-capital ratio $\left(Y_{t} / K_{t}\right)$, while capital accumulation is given by:

$$
K_{t+1}=(1-\delta) K_{t}+I_{t+1}
$$

where $0<\delta<1$ is the constant rate of capital depreciation. Labour demand $L_{t}$ equals total output over labour productivity $a_{t}$.

$$
L_{t}=\frac{Y_{t}}{a_{t}}
$$

Labour productivity grows at a constant, exogenous rate $\alpha>0$ :

$$
a_{t+1}=a_{t}(1+\alpha)
$$

The current wage rate depends on lagged wages plus a correction factor consisting in the difference between the past employment rate and the "equilibrium" value, i.e. the zero wage-inflation rate of employment (nowadays one would say the NAIRU with zero inflation):

$$
w_{t+1}=w_{t}\left(1+\lambda\left(v_{t}-\bar{v}\right)\right)
$$

where $\lambda \in(0,1)$ parametrizes the strength of workers' reaction to labour market disequilibria. Differently from the linearized Phillips curve ${ }^{4}$ present in Goodwin (1967), in our

\footnotetext{
${ }^{4}$ In fact, the labour market equation of the Growth Cycle, being expressed in real terms, is not exactly a Phillips curve which is a negative relation between changes in money wages and the unemployment rate. It lies in between the Phillips curve and the so called Wage curve, i.e. a real relation between the levels of real wages and the unemployment rate (see Blanchflower and Oswald, 1994).
} 
equation, the coefficient multiplies the deviation from "equilibrium". The employment rate is defined as the ratio of total labour demand over labour supply:

$$
v_{t}=\frac{L_{t}}{N_{t}}=\frac{Y_{t}}{N_{t} a_{t}}=\frac{A K_{t}}{N_{t} a_{t}}
$$

Population is assumed to grow at a constant rate $\beta>0$ :

$$
N_{t+1}=N_{t}(1+\beta)
$$

Finally, investment $I_{t+1}$ depends upon aggregate profits $\Pi_{t}$ gained in the previous period which are completely reinvested in the following period:

$$
I_{t+1}=\Pi_{t}=Y_{t}\left(1-u_{t}\right)
$$

where $u_{t}$ is the workers' share in output:

$$
u_{t}=\frac{W_{t}}{Y_{t}}=\frac{W_{t}}{L_{t} a_{t}}=\frac{w_{t}}{a_{t}}
$$

Rewriting the system in terms of $v_{t}$ and $u_{t}$ we obtain a system of two equations in two variables, with six parameters:

$$
\left\{\begin{array}{l}
\frac{v_{t+1}}{v_{t}}=\frac{K_{t+1}}{K_{t}} \frac{N_{t}}{N_{t+1}} \frac{a_{t}}{a_{t+1}}=\frac{1-\delta+A\left(1-u_{t}\right)}{(1+\alpha)(1+\beta)} \\
\frac{u_{t+1}}{u_{t}}=\frac{w_{t+1}}{w_{t}} \frac{a_{t}}{a_{t+1}}=\frac{\left(1+\lambda\left(v_{t}-\bar{v}\right)\right)}{1+\alpha}
\end{array}\right.
$$

It is formally a predator-prey relation between wage share and employment rate. In order to study the property of the system, let us perform the usual analysis of its fixed points. The system presents a unique non-negative fixed point:

$$
\left(v^{*}, u^{*}\right)=\left(\frac{\alpha+\lambda \bar{v}}{\lambda}, 1-\frac{\delta+g}{A}\right)
$$

where $g=\alpha+\beta+\alpha \beta$. It is easy to verify that the non-trivial fixed point is an unstable focus. Unfortunately, this discretization has destroyed the topological properties of the continuous time Goodwin model. Via simulations, we find that the variables manifest explosive behaviours. Thus the system left to itself is not able to reproduce any persistent regular cyclicity (see fig. 1.a and 1.b). Indeed, the Goodwin Growth Cycle does not appear to be robust to the discretization, corroborating similar results obtained in Sordi (1999). ${ }^{5}$

\footnotetext{
${ }^{5}$ As compared to the original Goodwin model, we have introduced two slightly modifications: a depreciation factor and an "expectation augmented" Phillips curve (where expectations are adaptive, i.e. the expected wage level equals the past experienced one). Nonetheless, the former brings a dampening factor (in fact the explosive behaviour is still present, and it would be even much more evident with a zero depreciation rate). The latter change does not alter the qualitative behaviour of the the Phillips curve discussed in Goodwin (1967), and it takes fully on board lags in wage setting.
} 


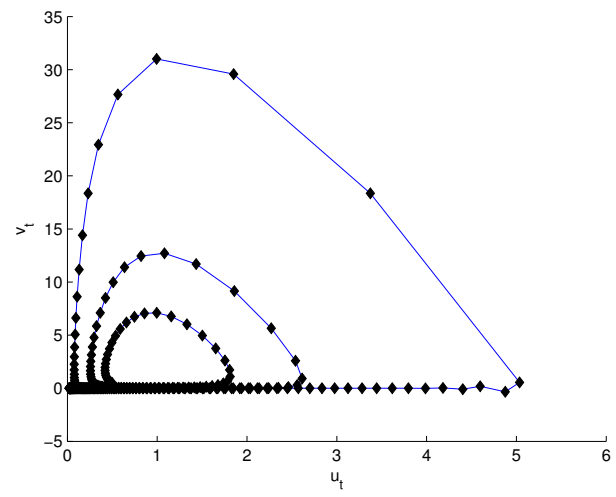

(a) Phase plane: after a finite number of iterations, the trajectories in the state space become unfeasible.

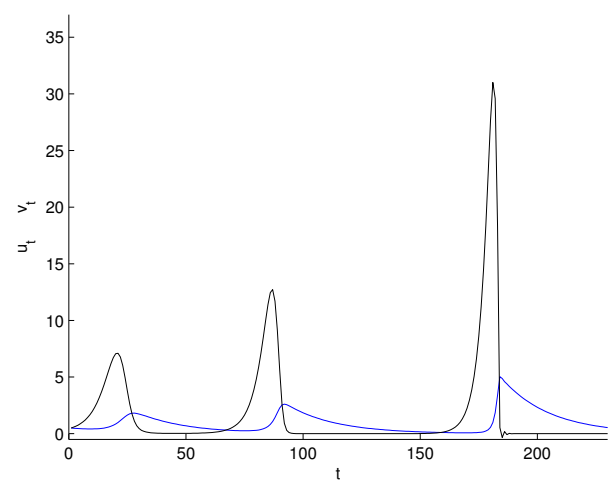

(b) Explosive oscillations in $u$ (blue line) and $v$ (black-line).

Figure 1: Goodwin discrete time model.

Parameters values: $A=0.5, \alpha=0.02, \beta=0.01, \delta=0.02, \lambda=0.03, \bar{v}=0.95$

\section{$5 \quad$ A generalized Goodwin plus Keynes model}

Let us address the structural instability and analyze a generalized discrete time model involving full coupled dynamics between wages, investment and income.

For these purposes, let us define the following variables:

$$
\begin{gathered}
y_{t}=\frac{Y_{t}}{N}=\psi v_{t} \\
w_{t}=\psi u_{t}
\end{gathered}
$$

and without loss of generality, assume a zero exogenous rate of growth of productivity, (i.e. a constant productivity $\psi$ ) and constant population $N$. We may thus rewrite the system (10) in terms of per capita income and wage rate:

$$
\left\{\begin{array}{l}
\frac{y_{t+1}}{y_{t}}=\frac{\psi(1-\delta)+A\left(\psi-w_{t}\right)}{\psi} \\
\frac{w_{t+1}}{w_{t}}=\frac{(1-\lambda \bar{v}) \psi+\lambda y_{t}}{\psi}
\end{array}\right.
$$

whereby the internal fixed point reads as:

$$
\left(y^{*}, w^{*}\right)=\left(\psi \bar{v}, \psi\left(\frac{A-\delta}{A}\right)\right)
$$

As already observed, the original Goodwin system can be expressed in the discrete formalization as: 


$$
\left\{\begin{array}{l}
\frac{y_{t+1}-y_{t}}{y_{t}}=\hat{F}\left(w_{t}\right)=\hat{b} w_{t}+\hat{e} \\
\frac{w_{t+1}-w_{t}}{w_{t}}=\hat{G}\left(y_{t}\right)=\hat{d} y_{t}+\hat{f}
\end{array}\right.
$$

where the parameters read as:

$$
\begin{gathered}
\hat{b}=-\frac{A}{\psi}, \quad \hat{e}=A-\delta \\
\hat{d}=\frac{\lambda}{\psi}, \quad \hat{f}=-\lambda \bar{v}
\end{gathered}
$$

A similar kind of discretization process is used by Goodwin (1989). In such a LotkaVolterra framework, $b<0$ and $d>0$, and of course the variation rate of each variable depends only upon the level of the other variable.

A major tenet of any genuine demand-driven model entails the dependency of investment upon actual aggregate income. In line with Kaldor $(1940)^{6}$ and the refinements in Kaldor and Mirrlees (1962), let us assume an accelerator process on investment, whereby investment depends on income level (and not on the variation such as in Samuelson, 1939b). After all, as pointed out by Kalecki:

The most controversial of the assumptions underlying [business cycle] models are those concerning the determinants of investment decisions. The rate of investment decisions is assumed in some theories to be determined by the rate of change in income (or output) and in some by the level of income. Indeed the problem of determinants of investment belongs probably to the least explored subjects of modern economics. (Kalecki, 1949)

Income distribution however affects investment themselves, via profits (and as a consequence, savings):

$$
\frac{I_{t+1}}{Y_{t}}=\left(1-u_{t}\right)+v Y_{t}
$$

with $v$ as the "accelerator" coefficient, yielding the capital accumulation process:

$$
K_{t+1}=(1-\delta) K_{t}+Y_{t}\left(1-u_{t}\right)+v Y_{t}^{2}
$$

Ultimately profits and aggregate demand exert together an effect on output growth rate. Rearranging (20) in terms of per capita income (recalling that $Y_{t}=A K_{t}$ and $w_{t}=\psi u_{t}$ ) we get:

$$
\frac{y_{t+1}-y_{t}}{y_{t}}=a y_{t}+b w_{t}+e
$$

\footnotetext{
${ }^{6}$ In Kaldor and Mirrlees (1962) the investment function expressed in continuous time is $I / Y=$ $v(Y-W)$. The significant advantage of our formulation is that we explicitly separate the income distribution/Goodwinian component from the demand/Keynesian one.
} 
On the side of product and labour markets firms are taken to be able to fix their prices via some murk-up rule upon unit labour costs, which adjust upon wages, which in turn are partly indexed on past prices. Hence assume that the (real) wage rate variation is affected by the previous price level:

$$
\frac{w_{t+1}-w_{t}}{w_{t}}=\eta p_{t}+d y_{t}+f
$$

where:

$$
p_{t}=\left(\frac{1+\mu}{\psi}\right) w_{t}
$$

$\mu>0$ is the mark-up and $\psi$ is the labour productivity, here both considered as constants. This implies that the wage growth depends also upon its previous level:

$$
\frac{w_{t+1}-w_{t}}{w_{t}}=\eta\left(\frac{1+\mu}{\psi}\right) w_{t}+d y_{t}+f=c w_{t}+d y_{t}+f
$$

where $c=\eta\left(\frac{1+\mu}{\psi}\right)$. Ultimately, such a Goodwin (or Marx) plus Keynes system yields a model entailing reciprocal interdependencies of both variation rates on the levels of both variables of the form:

$$
\left\{\begin{array}{l}
\frac{y_{t+1}-y_{t}}{y_{t}}=F\left(y_{t}, w_{t}\right)=a y_{t}+b w_{t}+e \\
\frac{w_{t+1}-w_{t}}{w_{t}}=G\left(y_{t}, w_{t}\right)=c w_{t}+d y_{t}+f
\end{array}\right.
$$

The first equation describes the dynamics of output growth rate, and the second the dynamic of wage growth rate. Under this modelling set-up, both depend upon the level of wages $\left(w_{t}\right)$ and level of activity $\left(y_{t}\right)$ of the previous period. Comparing the formulation of the dynamical system in (16) and (25) we note that in system (25) our formulation introduces a dependence of the output (wage) growth rates on the output (wage) levels. Let us consider the possible economic interpretation of the parameters in this framework (somewhat in tune with Medio, 1979).

1. $\frac{\partial F\left(y_{t}, w_{t}\right)}{\partial w_{t}}=b$ : let us call it the "profits effect" since in the "classical" regime the higher the level of wages, the lower will be the output growth rate, because reduction in the profit margin will decrease resources available for investment activity. For any given output-capital ratio, higher wages will yield to lower rates of investment. In this case $b$ is negative $(b<0)$. In a "pure Keynesian" regime the effect is nil $(b=0)$ (and in the real world may possibly even be negative).

2. $\frac{\partial F\left(y_{t}, w_{t}\right)}{\partial y_{t}}=a$ : call it the "demand effect" which is positive $(a>0)$, under any form of Keynesian multiplier/accelerator process while it is zero or negative 
$(a \leq 0)$, under a "classical" accumulation regime in that it indirectly captures the negative impact that high incomes (and thus a large wage bill) exert on the rates of investment and hence on growth.

3. $\frac{\partial G\left(y_{t}, w_{t}\right)}{\partial y_{t}}=d$ : it stands for the "employment effect" captured by the Phillips curve. The higher the level of activity, the higher the wage rate variations. It embodies the assumption that workers' bargaining power positively depends upon the level of employment, hence $d>0$.

4. $\frac{\partial G\left(y_{t}, w_{t}\right)}{\partial w_{t}}=c$ : it represents a "mark-up" effect which will take value zero $(c=0)$ under a "pure Classical/Marxian" regime. With mark-up pricing, capitalists index prices on unit labour cost so that when monetary wage growth is higher than labour productivity they increase prices, and vice versa. Since the increase in prices is not immediately and possibly not fully compensated by an increase in monetary wages of the same magnitude, the real wage growth rate is lower (and of course possibly negative). Thus the price level depends upon the level of wages weighted by a mark up factor (see eq (23)). Hence it is straightforward to assume $c<0$.

5. The two constants stand for two autonomous components of the income and wage growth rate. The $e$ parameter captures the autonomous component of investment - at the risk of overtheorizing, the "animal spirits" of the capitalists -. Here we assume it to be positive $(e>0)$. The $f$ stands for the vertical intercept of the linearised Phillips curve. It is negative $(f<0)$ under the classical wage formation mechanism.

\subsection{System dynamics under different regimes}

The analysis of the system dynamics means the study of the map:

$$
\left\{\begin{array}{l}
y_{t+1}=a y_{t}^{2}+b y_{t} w_{t}+(e+1) y_{t} \\
w_{t+1}=c w_{t}^{2}+d y_{t} w_{t}+(f+1) w_{t}
\end{array}\right.
$$

A complete characterization of the properties of the map is beyond the aim of the present work. Here we only focus on dynamic behaviour that have interesting implications in terms of "business cycle" phenomena. System (26) has four fixed points, but among them only the point

$$
\left(y^{*}, w^{*}\right)=\left(\frac{b f-e c}{c a-b d},-\frac{-d e+f a}{c a-b d}\right)
$$

is economically meaningful (the other ones have at least a zero coordinate). Thus we will only consider parameter configurations such that $y^{*}>0$ and $w^{*}>0$. The more 


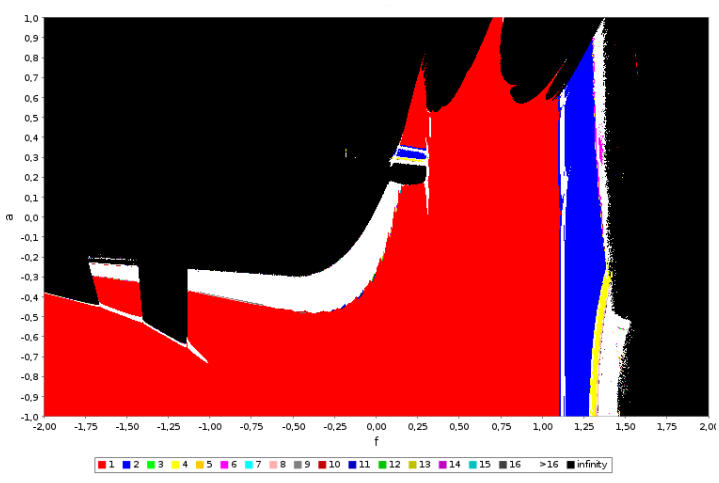

Figure 2: Two parameters $a$ and $f$ bifurcation diagram. Different colours stand for different dynamical behaviours .

- Stability region ם Unstable region • Period-2 cycle ฉ Period-4 cycle • Explosive oscillations

technical details of such investigation are in Appendix A.

Let us consider by means of simulation exercises the emergence of alternative regimes in terms of profits accumulation and growth $(b<0)$ under different "accelerator" (or "anti-accelerator") set-ups - i.e. positive or negative values of $a-$, governance regime on the labour market - i.e. positive or negative $f-$ and price-fixing mechanisms ( $c=0$ or $c<0$ ). The behaviour of the model is well-summarized by the two parameters bifurcation diagram in fig. 2 which shows different periodicity in the long run dynamic of the system, given initial conditions. The red area shows the combinations of the parameter values where the system is stable; the white area represents the regions of the parameters where occur the passage from stability to instability (possible emergence of the Neimark-Sacker bifurcation and of chaotic dynamic); the blue area the regions of period-2 cycle; the yellow area the parameters regions of period- 4 cycles. Finally the black one shows the combination of $a$ and $f$ that determines divergent oscillations.

\subsection{Stable regimes: "Victorian" versus "Keynesian" nexus}

Analysing figure 2, it is crucial to underline the emergence of the stability phase of the system in two opposite and complementary areas: one is characterised by strongly negative values of the "accelerator" parameter $a$ and of the linearised Phillips curve parameter $f$ (horizontal red area), the other one conversely raises for positive values of both $a$ and $f$ (vertical red area). The implications of such a result are quite remarkable: the system is able to reach two stable equilibrium states: a "Victorian" and a "Keynesian" one, both for a wide set of $a$ and $f$. Indeed a model where the sources of growth (technical progress and population) are shut down has to exhibit a stable pattern of convergence 
toward a fixed point. Interestingly this convergence strongly leaks out or in the area of a matching between the product and the labour market regime stuck in the competitive wage-labour nexus or at the opposite in the matching phase of the two markets trapped in the "corporatist-Keynesian" nexus. The two stable regimes actually captures long run dynamics. In fact the convergence toward a stable equilibrium pattern (just to recall, the red area) is by far the most "generic" behaviour of the system. The "Goodwinian" phase occurs as a transition state from one phase to the other (historically from the "Victorian" to the "corporatist-Keynesian" regime): it is actually a transitory phenomenon that captures short-run, business cycle fluctuations. The stable equilibrium point, reached in one of the two accumulation regimes above described, looses its stability. The trajectories of the system start oscillating with a quasi-periodic motion. The two markets, which actually represent capitalists and workers, are still in a matching condition but the coordination occurs by means of conflicting and opposite claims. Let us consider in more detail a "Goodwinian" set-up with classic profit-led accumulation $(b<0)$, an "antiaccelerator" $(a<0)$, price-taking firms $(c=0)$, a Phillips mechanism on the labour market $(d>0)$. Further we parametrize $e>0$, and study its dynamic for different values of $f$ (basically capturing the NAIRU) ${ }^{7}$. As shown by the Neimark-Sacker bifurcation diagram (fig. 3.a) the fixed point $\left(y_{4}^{*}, w_{4}^{*}\right)$ is the unique attractor of the system for $f<-1,5$. Trajectories starting in the gray region of fig. $3 . \mathrm{d}$ will converge to the invariant curve for $f=-1.5$ (see 3.d). Conversely, trajectories starting in the white region will diverge.

\subsection{Chaotic regime}

Interestingly, the relative order in the dynamics implied by the quasi-periodic fluctuations (see fig. 3.b) of the "classic" set-up tends to be disrupted in a presence of a mis-matching between labour-and product-markets $(a<0$ and $f>0)$. The absence of coordination in the two markets is basically traceable in the coexistence of under-investment decision of profits and over-indexation of wages. Consider, for example, parametrization $a=$ $-0.6, b=-0.92, c=-0.37, d=0.84, e=0.9$. For these values of parameters, below a threshold value of $f$, the fixed point $\left(y_{2}^{*}, w_{2}^{*}\right)$ is stable, above which, the fixed point undergoes a flip bifurcation (see 4.a). This is followed by a sequence of period doubling bifurcations that eventually generates a chaotic attractor (see fig. 4.b and 4.c). Chaotic orbits never converge to a stable fixed or periodic point, but exhibit sustained instability, while remaining forever in a bounded region of the state space. They are, as it were, trapped unstable orbits.

\footnotetext{
${ }^{7}$ The parameter setting we explore to capture the Goodwinian set-up is $a=-0.29, b=-0.92, c=$ $0, d=0.87, e=0.8, f=-1.5$.
} 


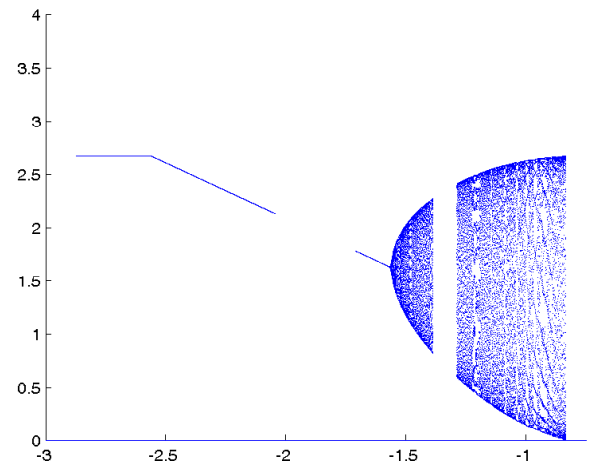

(a) Neimark-Sacker bifurcation on $w_{t}$. The bifurcation diagram shows that increasing values of $f$ may destabilize the internal point. After the occurrence of the bifurcation quasi-periodic orbits describe the long run behaviour of the system. Further increases in $f$ make the stationary state stable again.

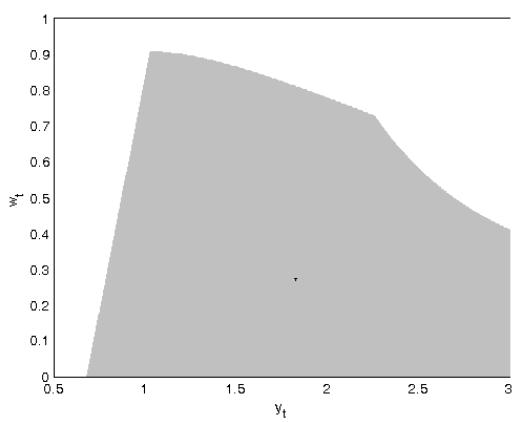

(c) The unique stable fixed point

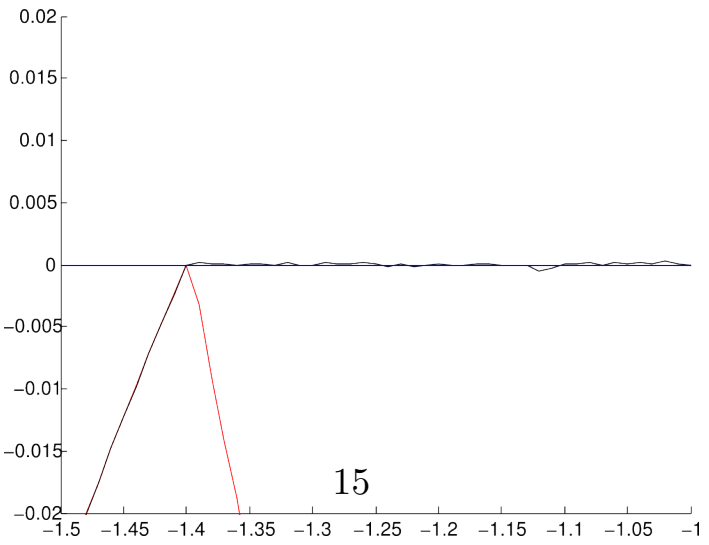

(e) Lyapanouv exponent ${ }^{8}$

Figure 3: The "quasi-Goodwinian" phase of the system.

Parameters values: $a=-0.29, b=-0.92, c=0, d=0.87, e=0.8, f=-1.5$. (b) Periodic oscillations of $w$ (black line) and $y$ (blue line).

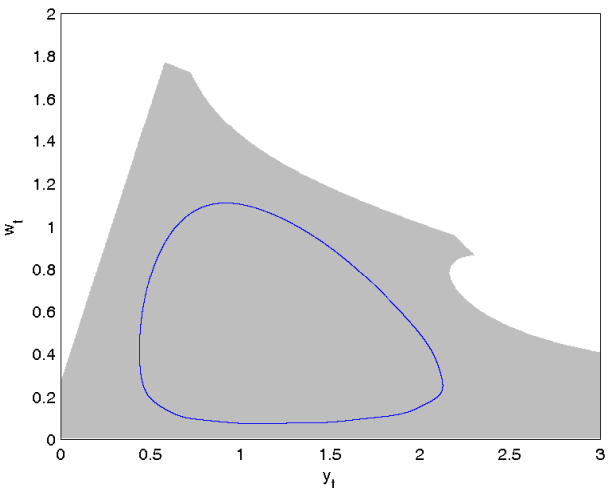

(d) The limit cycle relative to the Neimark-Sacker bifurcation. The gray region depicts its basin of attraction. Trajectories in the white region are divergent. 


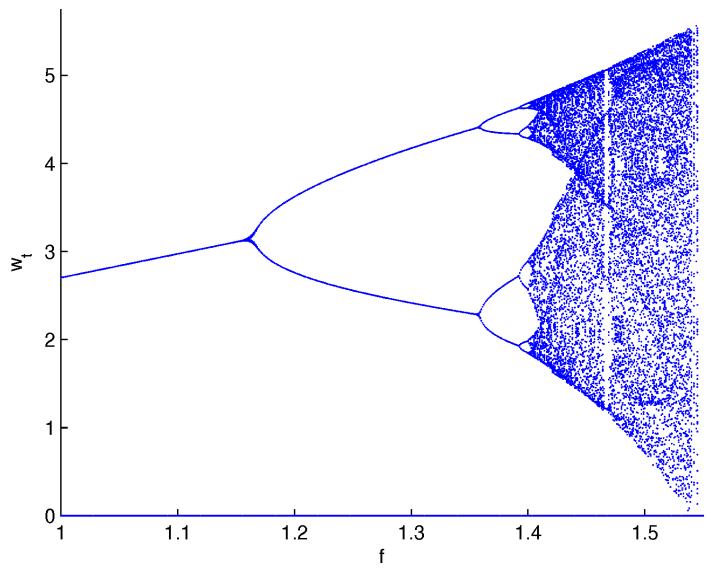

(a) Period doubling bifurcations: routes to chaos.

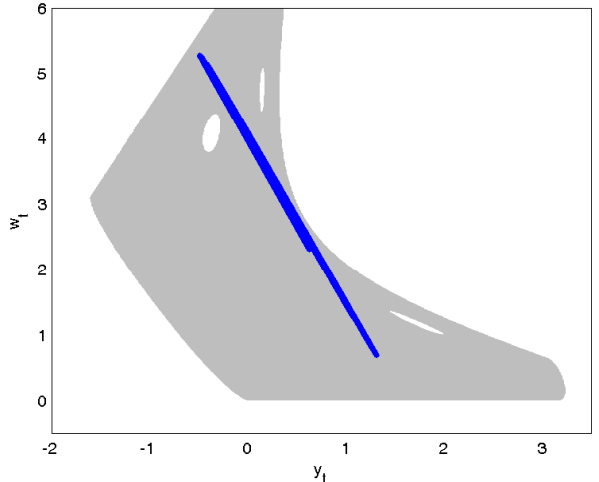

(b) Henon-like attractor. Chaotic regime.

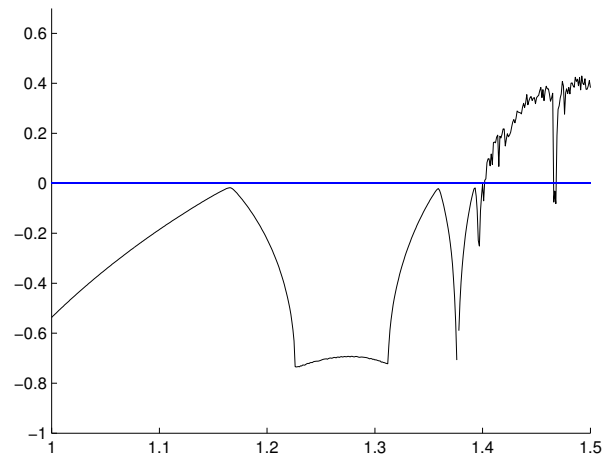

(c) The Maximal Lyapunov exponent shows the emergence of a chaotic attractor for $f>1.4$.

Figure 4: "Classic" investment dynamics with path-dependent wages and price making firms. Parameters values: $a=-0.6, b=-0.92, c=-0.37, d=0.84, e=0.9, f=1.41$. 


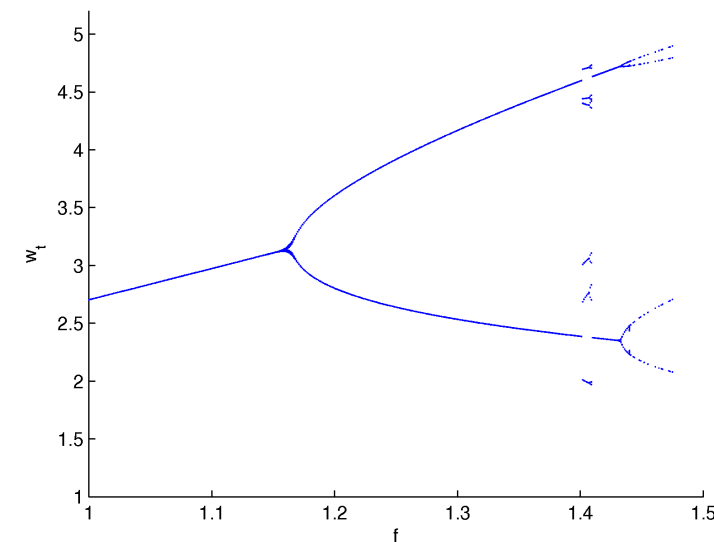

(a) Discontinuity in the bifurcation diagram shows the coexistence of multiple attractors: the same initial condition previously captured by a period 2cycle, for $f \in[1.39,1.42]$ enters the basin of an other attractor.

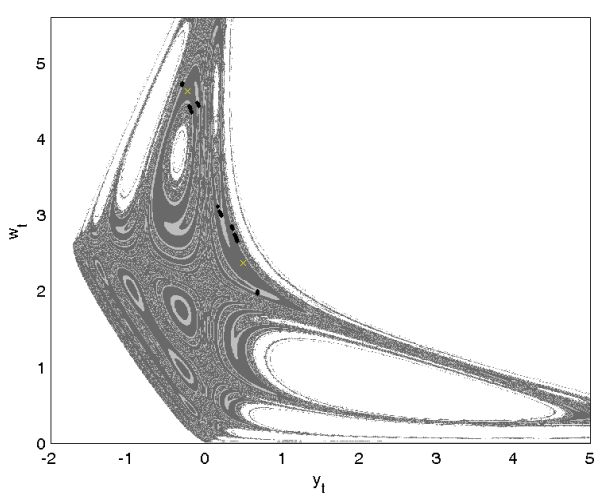

(b) Basin of coexisting attractors. The stucture of the basins is tangled.

Figure 5: Coexistence of attractors

Parameters values: $a=-0.3, b=-0.92, c=-0.37, d=0.84, e=0.9, f=1.41$.

In fact, chaotic dynamics emerge in one region: in presence of positive, high level of $f$. Let us recall the meaning of the parameter $f$ that is the vertical intercept of the linearized Phillips curve. The region in which a cycle emerges (the white area in the left hand side of fig. 2), where a form of stability (even though fluctuating) exists, is the region where $f$ is negative. Since the parameter enters the linearized Phillips curve with a negative specification, it relates to the threshold above which the monetary wage growth rate will become inflationary after having passed the NAIRU threshold. We are exactly in the area where the main properties of the profit-led economy described by Goodwin are valid. The economy is profit-led and wages negatively affect output growth. Conversely, the system enters into a period-doubling bifurcation when $f$ is higher than unity. In this region the value of the parameter $f$ entails a form of hysteresis whereby past wage level affects current one. Interestingly, note also that for higher values of $a$, (i.e. a milder "anti-accelerator", $a=-0.3$ ), coexisting attractors emerge (see fig. 5.b), obviously entailing path dependence.

\subsection{A good and a bad regime}

What happens on the contrary to a "predominantly Keynesian" system, displaying accelerator-led growth $(a>0)$, price-making firms $(c<0)$ and inflationary wage setting mechanism $(f>0)$ ? It exhibits a persistent stable dynamic for wide ranges of $a$ and $f$. 
The system looses stability when the wage-indexation mechanism is too strong relatively to the accelerator components. If the workers wage claims cannot be sustained by the production of goods, this will translate into a process of disinvestment hence of increase of unemployment, leading to a clear collapse of the system, trapped in a bad regime with low wages but also low profits. Recall that differently from the "Goodwinian" set-up, in the "corporatist" one wages, via demand, are more a source of profit-expansion, rather than a source of profit-squeezing. A possible way-out is conversely stimulating the investment activity to sustain production, employment and wages. The emergence of a good and a bad trajectories is strongly evident in figure 6 where we study the above dynamic properties under parametrization $a=0.45, b=-0.8, c=-0.37, d=0.84, e=0.9$. The fixed point undergoes a flip bifurcation when $f=1.34$, ending in a Neimark-Sacker bifurcation in both branches when $f=1.61$ (see fig. 6.a), involving again quasi-periodic orbits (see fig. 6.b). Here, the "Keynesian", "wage-driven" regime can push the system into two alternative states clearly, hinting at the possibility of a regime-switching via modification of the nexus between profits and wages.

\section{Conclusions}

Profit-led and demand-led models of endogenous fluctuations and growth tend to historically capture two distinct regimes of capital accumulation and of governance of the major markets (for labour, products, etc.). The former models - of which Goodwin's (1967) Growth Cycle is a seminal example - address a "Classic/Marxian" form of capitalism, grounded on competitive price-taking firms, which reinvest their profits, and draw upon an equally competitive labour market.

Conversely Keynesian accelerator/multiplier models find their empirical reference in regimes of capitalist organization characterized by price-making oligopolistic firms which invest according to the demand for their products and draw upon a supply of collectively organized labour, able to some extent to bargain wages independently from labour market conditions.

What happens, however, if one considers at the same time profit-related and demandrelated drivers of accumulation and growth?

Here, we proposed a formalization centered on the coupled dynamics between wages and aggregate income, whose parametrization tries to capture the double nature of wages themselves as element of costs and as a fundamental component of effective demand. The model exhibits a rich dynamic behaviour and in specific parameters regions yields quasi-periodic orbits, bifurcations and chaos. In particular, the system tends to be relatively orderly, at least in the weak sense of exhibiting exhibiting quasi-periodic orbits, whenever some consistency conditions between the patterns of accumulation and the 


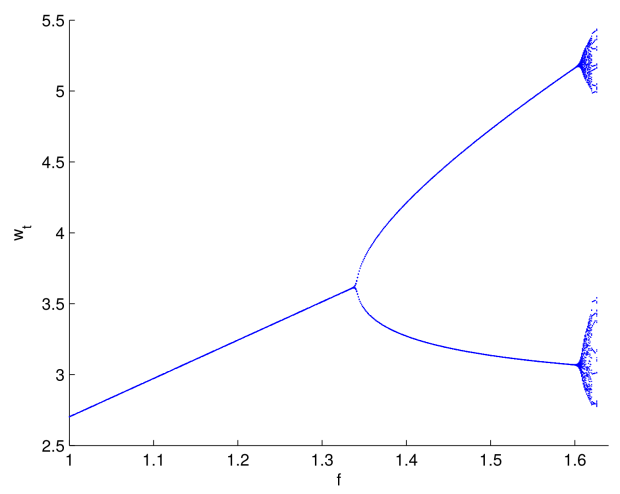

(a) Flip bifurcation ending in a Neimark-Sacker: a good and a bad regime.

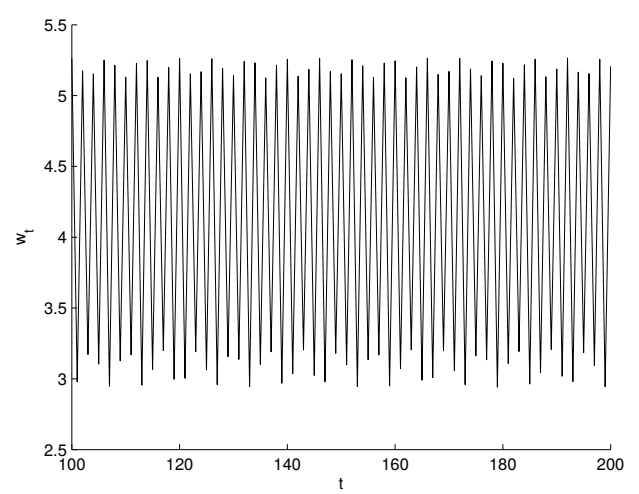

(b) Quasi-periodic orbits in the Neimark-Sacker phase of the system.

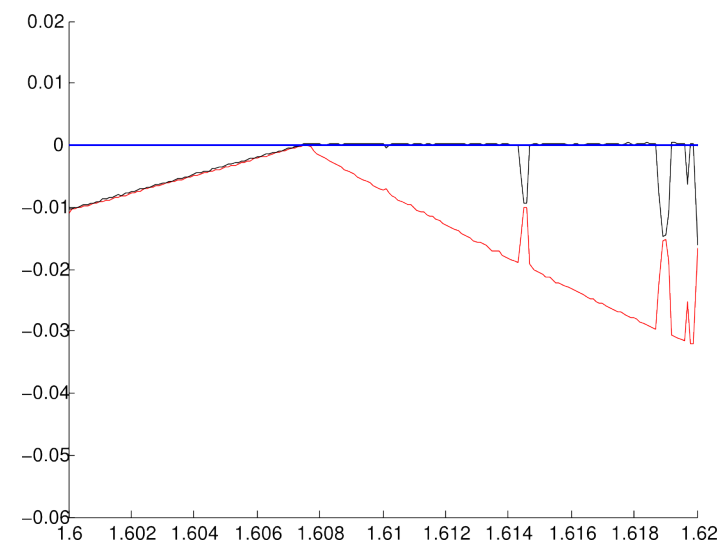

(c) Lyapounov exponent.

Figure 6: "Keynesian regime".

Parameters values: $a=0.45, b=-0.8, c=-0.37, d=0.84, e=0.9$. 
form of organization of the major markets are satisfied. It is a vindication of the notion of discrete regime of socio-economic regulation (Boyer, 1988b) whose inner "matching" or "mis-matching" determines their dynamic stability. Goodwin cycles appear under a profit-led ("anti-accelerator") accumulation regime, whenever this matches with pricetaking on the product market and unemployment-driven wage dynamics (a conclusion similiar to Lordon, 1995). Conversely, a relatively orderly dynamic appears again in a phase of the system characterized by accelerator-driven investment (and, thus, demanddriven growth) matched by price-setting in the product market and hysteresis in wage determination partly independent from labour market conditions. Moreover, interestingly, such a Keynesian set-up exhibits the coexistence of multiple attractors hinting at the multiplicity of growth paths whose selection plausibly depends on history and on public policies.

Where does one go from here? If one considers models such as the one presented here as sort of deterministic skeletons addressing some "laws of motion" linking aggregate variables (e.g. income, investment, unemployment, etc.), the challenge is to whether such "laws of motion" emerge out of micro-founded agent-based models (an example of the genre is in Napoletano et al., 2012). This is one of our tasks ahead.

\section{References}

Arthur, B., S. Durlauf, and D. Lane (1997). The Economy as an Evolving Complex System. Addison-Wesley.

Bhaduri, A. and S. Marglin (1990). "Unemployment and the real wage: the economic basis for contesting political ideologies". Cambridge Journal of Economics 14, 375393.

Bischi, G., L. Stefanini, and L. Gardini (1998). "Synchronization, intermittency and critical curves in duopoly games." Mathematics and Computers in Simulation 44.6, $559-585$.

Blanchflower, D. and A. Oswald (1994). The Wage Curve. The MIT Press Cambridge, Massachussets.

Boyer, R. (1988a). "Formalizing growth regime". Dosi et al. (1988), Pinter Publisher, London and New York.

Boyer, R. (1988b). "Technical change and theory of "Régulation"”. Dosi et al. (1988), Pinter Publisher, London and New York.

Canry, N. (2005). "Wage-Led Regime, Profit-Led Regime and Cycles: a Model". Economie Appliquée LVIII.1. 
Desai, M. (1974). "Growth Cycles and Inflation in a Model of the Class Struggle". Journal of Economic Theory 6.6, 527-545.

Domar, E. D. (1946). "Capital Expansion, Rate of Growth and Employment". Econometrica 14 (1), 137-147.

Dosi, G. et al. (1988). Technical change and Economic Theory. Pinter Publisher, London and New York.

Flaschel, P. (1984). "Some Stability Properties of Goodwin's Growth Cycle. A Critical Elaboration." Zeitschrift für Nationalökonomie 44 (1), 63-69.

Frisch, R. (1933). "Propagation Problems and Impulse Problems in Dynamic Economics". Essays in Honor of Gustav Cassel. Allen and Unwin, 171-3, 181-90, 197-203.

Goodwin, R. (1951). "The nonlinear accelerator and the persistence of business cycles". Econometrica 19, 1-17.

Goodwin, R. (1967). "A Growth Cycle". Socialism, Capitalism and Economic Growth. Feinstein, C. H., 54-58.

Goodwin, R. (1989). Chaotic Economic Dynamics. Oxford University Press.

Harrod, R. F. (1939). "An Essay in Dynamic Theory". The Economic Journal 49.193, $14-33$.

Kaldor, N. (1940). "A Model of the Trade Cycle". The Economic Journal 50.197, 78-92.

Kaldor, N. and J. Mirrlees (1962). "A New Model of Economic Growth". The Review of Economic Studies 29.3, 174-192.

Kalecki, M. (1935). "A Macrodynamic Theory of Business Cycles". Econometrica 3.3, $327-344$

Kalecki, M. (1949). "A New Approach to the Problem of Business Cycles". The Review of Economic Studies 16.2, 57-64.

Kirman, A. (2011). Complex Economics. Individual and Collective Rationality. Routledge.

Kuh, E. (1967). "A Productivity Theory of Wage Levels: an Alternative to the Phillips Curve". Review of Economic Studies 34, 333-360.

Lordon, F. (1995). "Cycles et chaos dans un modèle hétérodoxe de croissance endogène". Revue économique 46.6, 1405-1432.

Lorenz, H. W. (1993). Nonlinear Dynamical Economics and Chaotic Motion. Springer. 
Louca, F. (2001). "Intriguing pendula: founding metaphors in the analysis of economic fluctuations." Cambridge Journal of Economics 25.1, 25-45.

Manfredi, P. and L. Fanti (1999). "Cycles in continuous-time economic models (with applications to Goodwin's and Solow's models)". 2003/9.

Medio, A. (1979). Teoria nonlineare del ciclo economico. Bologna, Il Mulino.

Medio, A. (1992). Chaotic Dynamics: Theory and Applications to Economics. Cambridge University Press.

Napoletano, M., G. Dosi, G. Fagiolo, and A. Roventini (2012). "Wage Formation, Investment Behavior and Growth Regimes: An Agent-Based Analysis". Revue de l'OFCE $0.5,235-261$.

Nicolis, G. and I. Prigogine (1977). Self-organization in nonequilibrium systems: from dissipative structures to order through fluctuations. Wiley.

Pasinetti, L. (1960). "Cyclical Fluctuations and Economic Growth". Oxford Economic Papers 12.2, 215-241.

Pohjola, M. (1981). "Stable, Cyclic and Chaotic Growth: The Dynamics of a DiscreteTime Version of Goodwin's Growth Cycle". Zeitschrift für Nationalökonomie 41 (1-2), $27-38$.

Puu, T. and I. Sushko (2006). Business Cycle Dynamics: Models and Tools. Springer.

Rosser, B. (1999). "On the Complexities of Complex Economic Dynamics". Journal of Economic Perspectives 13.4, 169-192.

Samuelson, P. (1939a). "A Synthesis of the Principle of Acceleration and the Multiplier". The Journal of Political Economy 47.6, 786-797.

Samuelson, P. (1939b). "Interactions between the Multiplier Analysis and the Principle of Acceleration". The Review of Economics and Statistics 21.2, 75-78.

Schumpeter, J. (1934). The Theory of Economic Development: An inquiry into Profits, Capital, Credit, Interest and the Business Cycle. Transaction Books.

Silverberg, G. and D. Lehnert (1994). "Growth Fluctuations in an Evolutionary model of Creative Destruction". The Economics of Growth and Technical Change: Technologies, Nations, Agents. Ed. by G. Silverberg and L. Soete. Edward Elgar Aldershot, $74-108$.

Sordi, S. (1999). "Economic models and the relevance of "chaotic regions":An application to Goodwin's growth cycle model". Annals of Operations Research 89 (0), 3-19. 
Tebaldi, C. and G. Colacchio (2007). "Chaotic Behavior in a Modified Goodwin's Growth Cycle Model". Proceedings of the 25th International Conference of the System Dynamics Society and 50th Anniversary Celebration. System Dynamics Society.

Velupillai, K. (1979). "Some Stability Properties of Goodwin's Growth Cycle Model". Zeitschrift für Nationalökonomie 39.3-4, 245-257.

Whitley, D. (1983). "Discrete Dynamical Systems in Dimensions One and Two". Bulletin of the London Mathematical Society 15.3, 177-217.

Wolfstetter, E. (1982). "Fiscal Policy and the Classical Growth Cycle". Zeitschrift für Nationalökonomie 42.4, 375-393.

Yoshida, H. and T. Asada (2007). "Dynamic analysis of policy lag in a Keynes-Goodwin model: Stability, instability, cycles and chaos". Journal of Economic Behavior 83 Organization 62, 441-469.

\section{Appendix}

The study of local stability of equilibrium solutions is based on the Jacobian matrix of the dynamical system. The Jacobian matrix of (26) computed at a generic point has the form:

$$
\mathcal{J}=\left(\begin{array}{cc}
2 a y_{t}+b w_{t}+e+1 & b y_{t} \\
d w_{t} & 2 c w_{t}+d y_{t}+f+1
\end{array}\right)
$$

The stability conditions for a two dimensional map follow the usual characterization: a fixed point $(\bar{x}, \bar{y})$ is (locally) asymptotically stable if the eigenvalues $\lambda_{1}$ and $\lambda_{2}$ of the Jacobian matrix, calculated at the fixed point, are less than one in modulus. The necessary and sufficient conditions ensuring that $\left|\lambda_{1}\right|<1$ and $\left|\lambda_{2}\right|<1$ are:

$$
\begin{gathered}
1+\operatorname{Tr}\left(\mathcal{J}_{\bar{x}}\right)+\operatorname{det}\left(\mathcal{J}_{\bar{x}}\right)>0 \\
1-\operatorname{Tr}\left(\mathcal{J}_{\bar{x}}\right)+\operatorname{det}\left(\mathcal{J}_{\bar{x}}\right)>0 \\
1-\operatorname{det}\left(\mathcal{J}_{\bar{x}}\right)>0
\end{gathered}
$$

The violation of one of these conditions leads to the emergence of a local bifurcation. For a further detailed exposition on the nature of local bifurcations see Whitley (1983). Regarding the fixed point $\left(y^{*}, w^{*}\right)$, the analysis of stability conditions is not of easy treatment. ${ }^{9}$ At this point it is important to understand if the fixed point captures the

\footnotetext{
${ }^{9}$ For the requirement on the emergence of the Neimark-Sacker bifurcation see e.g. Lorenz (1993).
} 
trajectories generated by initial conditions enough close to the stationary solution, or if other dynamical behaviours characterize long run dynamics. In particular by studying the eigenvalues of the linearized dynamical system(inserire riferime) it is possible to have some insights on the emergence of oscillating persistent dynamics around the fixed point. In what follows, according to different parameter settings we will study the properties of the system letting the parameter $f$ varies.

Proposition 1. A necessary condition such that the internal equilibrium point $\left(y^{*}, w^{*}\right)=$ $\left(\frac{b f-e c}{c a-b d},-\frac{-d e+f a}{c a-b d}\right)$ undergoes a Neimark-Sacker bifurcation is the second degree polynomial:

$$
a f^{2} b+(c a-e b d-a b-a c e) f+e^{2} d c+a c e-c e d
$$

has to vanish with respect to $f$, such that the eigenvalues cross the unit circle.

Proof 1. follows from the analysis of the Jacobian matrix evaluated at the internal equilibrium point $\left(y^{*}, w^{*}\right)=\left(\frac{b f-e c}{c a-b d},-\frac{-d e+f a}{c a-b d}\right)$ :

$$
\left(\begin{array}{cc}
\frac{a b f-a c e-b d+c a}{-b d+c a} & \frac{(b f-c e) b}{-b d+c a} \\
\frac{(a f-e d) d}{-b d+c a} & -\frac{c a f-c e d+b d-c a}{-b d+c a}
\end{array}\right)
$$

